\title{
Extended criteria donors: Closer to the truth
}

\author{
Benjamin Wei, MD
}

\footnotetext{
From the Division of Cardiothoracic Surgery, Department of Surgery, University of Alabama Birmingham School of Medicine, Birmingham, Ala.

Disclosures: Author has nothing to disclose with regard to commercial support.

Received for publication May 9, 2016; accepted for publication May 9, 2016; available ahead of print May 28, 2016.

Address for reprints: Benjamin Wei, MD, Division of Cardiothoracic Surgery, Department of Surgery, University of Alabama Birmingham School of Medicine, ZRB 739, 1720 2nd Ave South, Birmingham, AL 35294-0007 (E-mail: bwei@uab.edu).

J Thorac Cardiovasc Surg 2016;152:899-900

0022-5223/\$0.00

Published by Elsevier Inc. on behalf of The American Association for Thoracic Surgery http://dx.doi.org/10.1016/j.jtcvs.2016.05.017
}

In this study of 11,000 lung transplants from 2005 to 2012 , Mulligan and colleagues ${ }^{1}$ have provided greater clarity to the definition and significance of using lungs from an extended criteria donor (ECD). Typical criteria for an ECD have included age more than 55 years, partial pressure of oxygen/fraction of inspired oxygen ratio less than 300 , abnormal radiographic findings, ischemic time more than 6 hours, smoking history more than 20 pack-years, chest trauma, abnormal bronchoscopic findings, and positive sputum microbiology. ${ }^{2,3}$ Some have shown that the use of lungs from ECDs is not associated with poorer outcomes, ${ }^{3}$ and others have found the reverse to be true. ${ }^{4}$

Now, we have more data about what constitutes an ECD for lung transplantation. In the study by Mulligan and colleagues, ${ }^{1}$ the largest one examining this issue to date, 4 criteria decreased the 1-year survival after lung transplant: age 65 years or more, 20 pack-years or more smoking history, diabetes, and African-American race. Having at least 1 of these criteria led to significantly decreased 1-year survival in both low-risk (lung allocation score $<70$ ) and high-risk (lung allocation score $>70$ ) recipients, from $87.3 \%$ to $82 \%$ and $79.6 \%$ to $71.7 \%$, respectively. Having 2 or more criteria further increased the hazard ratio of death.

This interaction between risk of the donor and risk of the recipient confirms what many would suspect, that high-risk patients who receive marginal lungs do poorly. Furthermore, a low-risk recipient who received an ECD lung had similar survival at 1 year as a high-risk recipient who received a lung from a standard donor. These findings give transplant pulmonologists and surgeons more information with which to base donor selection.

How, though, do we use this information? Do we shy away from using donors with these risk factors in low-risk recipients, high-recipients, neither, or both? A total of $35 \%$ of recipients during this time period received an ECD lung or lungs. This study did not compare the use of ECD lungs with no transplantation, but if we become

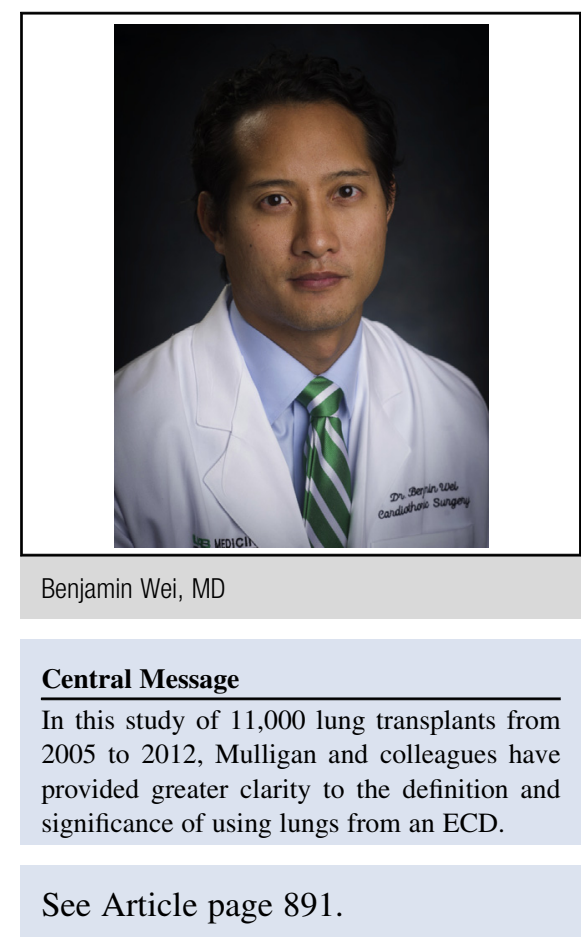

more selective about which donors to use, it is likely that fewer patients will receive transplants and more patients will die on the waiting list. On the flip side, what is not on the list of risk factors also is important: The fact that Mulligan and colleagues ${ }^{1}$ did not find radiologic, bronchoscopic, or laboratory criteria to confer worse survival perhaps suggests that we should give more consideration to donors for whom these studies are less than ideal.

Further questions arise: How does using a single lung from a standard donor compare with both lungs from an ECD? How about a single ECD lung versus bilateral ECD lungs? How does this interact with low-risk versus highrisk recipients? Are midterm and long-term allograft and patient survival affected by the use of ECD lungs by these criteria? Of note, this study also did not include recipients receiving donor after cardiac death lungs or recipients on extracorporeal membrane oxygenation, both increasingly common situations.

\section{References}

1. Mulligan MJ, Sanchez PG, Evans CF, Wang Y, Kon ZN, Rajagopal K, et al. The use of extended criteria donors decreases one-year survival in high-risk lung recipients: A review of the United Network of Organ Sharing Database. J Thorac Cardiovasc Surg. 2016;152:891-8.e2. 
2. Lardinois D, Banysch M, Korom S, Hillinger S, Rousson V, Boehler A, et al. Extended donor lungs: eleven years experience in a consecutive series. Eur J Cardiothorac Surg. 2005;27:762-7.

3. Moreno P, Alvarez A, Santos F, Vaquero JM, Baamonde C, Redel J, et al Extended recipients but not extended donors are associated with poor out- comes following lung transplantation. Eur J Cardiothorac Surg. 2014;45: 1040-7.

4. Smits JM, van der Bij W, Van Raemdonck D, de Vries E, Rahmel A, Laufer G, et al. Defining an extended criteria donor lung: an empirical approach based on the Eurotransplant experience. Transpl Int. 2011;24:393-400. 